\title{
Kinetic calibration of the calcium indicator arsenazo III. I. Stopped-flow spectroscopy
}

\author{
Stefanie Clemen, Carl-Roland Rabl and Eberhard Neumann \\ Physical and Biophysical Chemistry, Faculty of Chemistry, University of Bielefeld, Bielefeld (F.R.G.)
}

(Received 16 June 1987)

(Revised manuscript received 21 October 1987)

Key words: Arsenazo III; Calcium-arsenazo III complex; Kinetic calibration; Stopped flow

Stopped-flow studies of the calcium-arsenazo III (Ar) system exhibit reaction time constants ranging from 4 to $20 \mathrm{~ms}$, mainly caused by the formation of $\mathrm{CaAr}$ and $\mathrm{CaAr}_{2}$ complexes $\left([\mathrm{Ca}]_{0}=10 \mu \mathrm{M}\right.$ to $10 \mathrm{mM}$, $[A r]_{0}=10 \mu \mathrm{M}$ to $50 \mu \mathrm{M}$ ). At total concentrations $[\mathrm{Ca}]_{0} \geq 100 \mu \mathrm{M}$ an additional slow reaction mode with time constants of 100 to $600 \mathrm{~ms}$ has been found, which is attributed to the formation of the $\mathrm{Ca}_{2} \mathrm{Ar}$ complex according to $\mathrm{Ca}+\mathrm{CaAr} \rightleftharpoons \mathrm{Ca}_{2} \mathrm{Ar}$. The rate coefficients of association and dissociation are, respectively, $k_{+}=900 \mathrm{M}^{-1} \cdot \mathrm{s}^{-1}$ and $k_{-}=1.8 \mathrm{~s}^{-1}$, yielding $K=k_{+} / k_{-}=500 \mathrm{M}^{-1}$. In biophysics and cell biology arsenazo III may be used to monitor the kinetics of micromolar Ca-concentration changes in the time range $\geq 50 \mathrm{~ms}$. If the optical signal is properly deconvoluted, the time range may be extended to $5 \mathrm{~ms}$. An improved method for purifying arsenazo III is communicated.

\section{Introduction}

In cell biology and biophysics the metallochromic arsenazo III (Ar:2,7-bis(2-arsonophenylazo)-1,8-dihydroxynaphthalene-3,6-disulfonic acid) is a widely used dye indicator to monitor changes in the calcium concentration [Ca]; (see, for example, Ref. 1). Frequently a simple $1: 1$ stoichiometry of $\mathrm{Ca}^{2+}$ and $\mathrm{Ar}$ is assumed; the association equilibrium constant is $K \approx 5 \cdot 10^{4}$ $\mathbf{M}^{-1}$. The results of static titrations, however, suggested the formation of at least three complexes: $\mathrm{CaAr}, \mathrm{CaAr}_{2}$ and $\mathrm{Ca}_{2} \mathrm{Ar}$ [2]. Palade and Vergara [4] proposed that instead of the $\mathrm{Ca}_{2} \mathrm{Ar}$

Abbreviation: Pipes, 1,4-piperazinediethanesulfonic acid.

Correspondence: E. Neumann, Physical and Biophysical Chemistry, Faculty of Chemistry, University of Bielefeld, P.O. Box 8640, D-4800 Bielefeld 1, F.R.G. complex the $\mathrm{Ca}_{2} \mathrm{Ar}_{2}$ complex is formed. Detailed static and kinetic titrations using the temperature jump method revealed that besides $\mathrm{CaAr}, \mathrm{CaAr}_{2}$ and $\mathrm{Ca}_{2} \mathrm{Ar}_{2}$ the complexes $\mathrm{Ca}_{2} \mathrm{Ar}_{3}$ and $\mathrm{Ca}_{2} \mathrm{Ar}_{4}$ have to be also considered [5]; see also part II [6]. Because of the multiple complex formations any kinetic analysis of [Ca] changes indicated by $\mathrm{Ar}$, e.g. in biological cells or organelles, is rather elaborate. In order to obtain the actual rate of [Ca] changes due to a biological process, it is in general necessary to deconvolute the observed dye signal with the intrinsic rate constants of the $\mathrm{Ca}-\mathrm{Ar}$ reactions. In this study a more advanced stoppedflow set-up has been used in order to resolve the rather small signal changes of the Ca-Ar system in the time range 4 to $20 \mathrm{~ms}$. The main result is the discovery of an additional complex $\mathrm{Ca}_{2} \mathrm{Ar}$. In biological studies arsenazo III may be used to monitor the kinetics of micromolar Ca-concentration changes in the time range $\geq 50 \mathrm{~ms}$. If the optical signal is properly deconvoluted, the time 
range may be extended to $5 \mathrm{~ms}$. It is remarked that stopped-flow mixing technique is formally analogous to the local mixing of $\mathrm{Ca}$ ions with cell components after stimulated $\mathrm{Ca}$ influx.

\section{Materials and Methods}

Arsenazo III (Aldrich Chemical Co., Milwaukee) was at first purified by column chromatography [7]. A glass column $35 \mathrm{~cm} \times 3.5 \mathrm{~cm}$ was filled with Whatman DE 52 DEAE-cellulose and equilibrated with the eluent 2-butanol/pyridine/ acetic acid/water $(3: 1: 1: 3, \mathrm{v} / \mathrm{v})$ for $12 \mathrm{~h}$. At variance with Kendrick's proposal of $n$-butanol [7] the use of 2-butanol is essential for a homogeneous one-phase solution; $n$-butanol results in a phase separation which is not well suited for the separations. $450 \mathrm{mg}$ arsenazo III were dissolved in $2 \mathrm{ml}$ bidistilled water and $3 \mathrm{ml}$ eluent and applied to the column (eluation rate $14 \mathrm{ml} / \mathrm{h}$ ). The darkviolet fraction was collected and dried in vacuo. The dry powder was redissolved in water and applied to an ion exchange column (Chelex from Bio-Rad, 200-400 mesh, sodium form, bidistilled water as eluent). Arsenazo III was recrystallized by lyophilisation; the yield was $250 \mathrm{mg}$.

By atomic absorption spectroscopy (Pye Unicam Model SP 1900) the molar ratio Ca: Ar of the purified dye is 0.018 . The $\mathrm{Na}^{+}$salt of Pipes ( $\mathrm{pK}$ 6.8 at $25^{\circ} \mathrm{C}$ ) was used as a $\mathrm{pH}$ buffer. All vessels, including the stopped-flow apparatus, were carefully rinsed with $2 \mathrm{mM}$ EDTA-solution and finally with bidistilled water. Polyethylene vessels were used wherever feasible.

\section{Measurements}

The stopped-flow apparatus (design C.R. Rabl) was equipped with a $7 \mathrm{~mm}$ absorbance cell, a Si-photodiode and a log-converter. The mixing time (dead time, see Fig. 1) is $\approx 1 \mathrm{~ms}$. The total input concentrations were in the range $[\mathrm{Ar}]_{0}=10$ to $50 \mu \mathrm{M}$ and $[\mathrm{Ca}]_{o}=10 \mu \mathrm{M}$ to $10 \mathrm{mM} ; 30 \mathrm{mM}$ $\mathrm{Na}$-Pipes buffer at $\mathrm{pH} 7.0,20^{\circ} \mathrm{C}$. The absorbance signal $\Delta A_{602}$ was measured at the wavelength $\lambda=$ $602 \mathrm{~nm}$ and recorded from $0.2 \mathrm{~ms}$ to $8 \mathrm{~s}$ with a dual time base transient recorder (Bryans/Physical Data Model 523 A, 10 bit). On-line signal analysis, including a deconvolution for the apparatus risetime, was performed with a HewlettPackard computer Model 9816.

\section{Results}

A typical stopped-flow signal trace (after mixing $\mathrm{Ca}^{2+}$ with arsenazo III within $1 \mathrm{~ms}$ ) is shown in Fig. 1. Note that the time scale is logarithmic. The overall optical signal $\Delta A_{602}(t)$ was fitted in terms of exponential time constants $\tau_{i}$ and amplitudes $A_{i}$ according to the time ( $t$ ) function $S(t)$

$S(t)=A_{o}+\sum_{i} A_{i}\left(1-\exp \left(-t / \tau_{i}\right)\right) \quad i=1,2,3$

Two time constants were needed for the range $[\mathrm{Ca}]_{\circ} \leq 100 \mu \mathrm{M}$ and three time constants for $[\mathrm{Ca}]_{\circ}$ $>100 \mu \mathrm{M}$. The first two terms are found to be closely correlated: $\tau_{2}=2$ to $4 \tau_{1}$; the amplitude ratio $A_{2} / A_{1}$ is 1 to 2 for $[\mathrm{Ca}]_{0} \leq 70 \mu \mathrm{M}$ and decreases to 0.15 at high $[\mathrm{Ca}]_{o}$ values. For a sim-

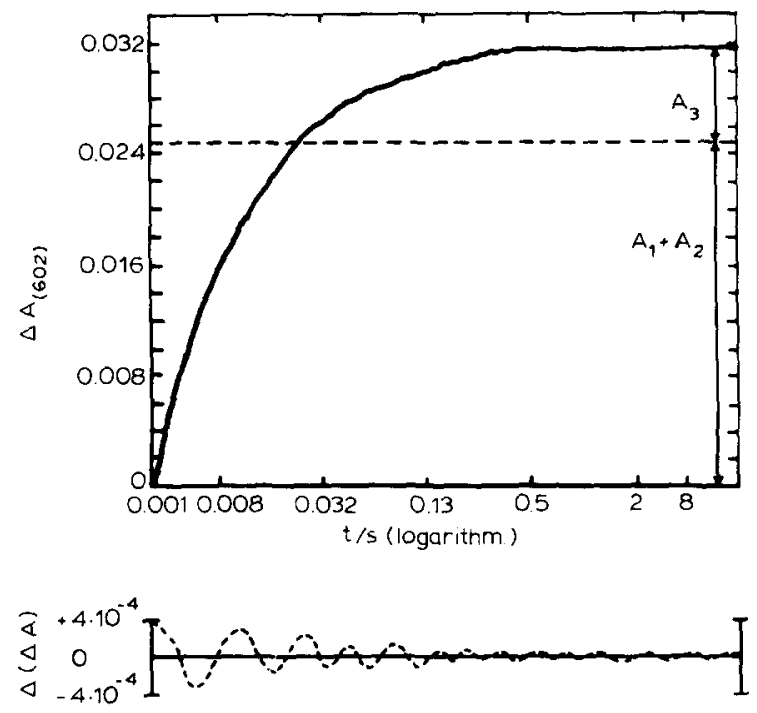

Fig. 1. Absorbance change $\Delta A_{602}$ at $\lambda=602 \mathrm{~nm}$ after mixing a solution of $[\mathrm{Ar}]_{\mathrm{o}}=15.8 \mu \mathrm{M}$ and of $[\mathrm{Ca}]_{\mathrm{o}}=5.62 \mathrm{mM}$ at $T=$ $20^{\circ} \mathrm{C}$ and $\mathrm{pH} 7.0$. The dead time is $1 \mathrm{~ms}$. Note the logarithmic time scale. The curve fitting leads to following parameters:

$\begin{array}{ll}\tau_{1}=4.53 \mathrm{~ms}, & A_{1}=0.0137 \\ \tau_{2}=14.8 \mathrm{~ms}, & A_{2}=0.0107 \\ \tau_{3}=124 \mathrm{~ms}, & A_{3}=0.00485\end{array}$

$A_{1}+A_{2}$ is the amplitude of the rapid phase, $A_{3}$ is the amplitude of the slow phase. $\Delta A=0$ refers to the initial level of $A_{602}=0.5234 . \Delta(\Delta A)=\Delta A_{602}(t)-S(t)$, see Eqn. 1 of the text. 


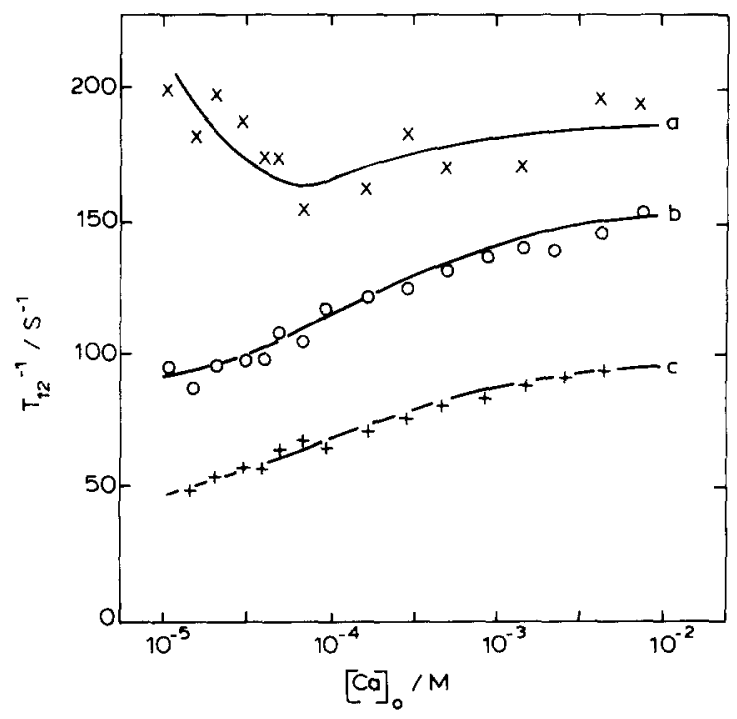

Fig. 2. The specific rate $1 / \tau_{12}$ as a function of the total $\mathrm{Ca}$ concentration at (a) $[\mathrm{Ar}]_{0}=10 \mu \mathrm{M}$, (b) $[\mathrm{Ar}]_{0}=25 \mu \mathrm{M}$, (c) $[\mathrm{Ar}]_{\mathrm{o}}=50 \mu \mathrm{M}$; Pipes buffer $\left(\mathrm{pH} \mathrm{7.0)}, 20^{\circ} \mathrm{C}, I_{\mathrm{c}}=30 \mathrm{mM}\right.$.

plified representation, the data are plotted in Fig. 2 in terms of the logarithmic average $\tau_{12}$ as defined by

$\ln \tau_{12}=\left(A_{1} / A_{12}\right) \ln \tau_{1}+\left(A_{2} / A_{12}\right) \ln \tau_{2}, A_{12}=A_{1}+A_{2}$

At present no simple evaluation can be given for this main relaxation effect.

The slow reaction mode $\tau_{3}=100$ to $600 \mathrm{~ms}$ at large $[\mathrm{Ca}]_{o}$ values has only a small amplitude $A_{3}$.

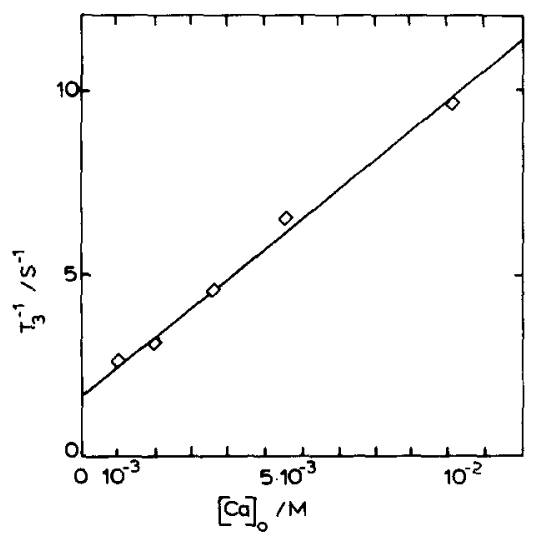

Fig. 3. The specific rate $1 / \tau_{3}$ as a function of the total $\mathrm{Ca}$ concentration. The symbols represent mean values for $[\mathrm{Ar}]_{0}=$ 10 to $50 \mu \mathrm{M}$; Pipes buffer (pH 7.0), $20^{\circ} \mathrm{C}, I_{\mathrm{c}}=30 \mathrm{mM}$.
TABLE I

REACTION PARAMETERS OF THE CALCIUMARSENAZO III SYSTEM

\begin{tabular}{|c|c|c|c|}
\hline Reaction & $\begin{array}{l}K_{i, \text { ass }} \\
\left(M^{-1}\right)\end{array}$ & $\begin{array}{l}k_{i+} \\
\left(\mathbf{M}^{-1}\right. \\
\left.\cdot \mathrm{s}^{-1}\right)\end{array}$ & $\begin{array}{l}\Delta \mathbf{\epsilon}_{i} \\
\left(\mathbf{M}^{-1}\right. \\
\left.\cdot \mathrm{cm}^{-1}\right)\end{array}$ \\
\hline $\overrightarrow{\mathrm{Na}+\mathrm{Ar} \rightleftharpoons \mathrm{NaAr}}$ & $4.7 \cdot 10^{1}$ & $6.7 \cdot 10^{3}$ & 3600 \\
\hline $\mathrm{Ca}+\mathrm{Ar} \rightleftharpoons \mathrm{CaAr}$ & $2.3 \cdot 10^{5}$ & $3.3 \cdot 10^{6}$ & 32300 \\
\hline $\mathrm{NaAr}+\mathrm{CaAr} \rightleftharpoons \mathrm{NaCaAr}_{2}$ & $2.1 \cdot 10^{4}$ & $1.0 \cdot 10^{7}$ & 14200 \\
\hline $\mathrm{Ca}+\mathrm{CaAr} \rightleftharpoons \mathrm{Ca}_{2} \mathrm{Ar}$ & $5.0 \cdot 10^{2}$ & $9.0 \cdot 10^{2}$ & 2180 \\
\hline $2 \mathrm{CaAr} \rightleftharpoons \mathrm{Ca}_{2} \mathrm{Ar}_{2}$ & $4.9 \cdot 10^{4}$ & $1.1 \cdot 10^{6}$ & 3700 \\
\hline
\end{tabular}

Under the given experimental conditions the specific rate $1 / \tau_{3}$ is essentially independent on $[\mathrm{Ar}]_{\mathrm{o}}$ and is consistent with the reaction scheme

$\mathrm{Ca}+\mathrm{CaAr} \rightleftharpoons \mathrm{Ca}_{2} \mathrm{Ar}$

Since $[\mathrm{Ca}]_{0} \gg[\mathrm{CaAr}],\left[\mathrm{Ca}_{2} \mathrm{Ar}\right]$, we may apply a pseudo-first-order approximation and express the time constant by the relaxation time of this reaction. Thus at $[\mathrm{Ca}]_{o} \geq 1 \mathrm{mM}, \tau_{3}=\left(k_{+}[\mathrm{Ca}]_{o}+\right.$ $\left.k_{-}\right)^{-1}$ being independent of $[\mathrm{Ar}]_{\mathrm{o}}$. From Fig. 3 we derive the rate constants of association $k_{+}=900$ $\mathrm{M}^{-1} \cdot \mathrm{s}^{-1}$ and of dissociation $k_{-}=1.8 \mathrm{~s}^{-1}$, respectively.

Based on the results of previous kinetic studies $[3,5]$ and on the present data of the $\mathrm{Ca}_{2} \mathrm{Ar}$ complex, a 'minimum model', fitted by variation of the association equilibrium constants $K_{i, \text { ass }}=$ $\mathrm{k}_{i+} / \mathbf{k}_{i-}$, rate constants $k_{i+}$ and the absorption coefficient differences $\Delta \epsilon_{i}$ (numerical integration on HP 9020 computer) is given in Table I. The absorption coefficient of $\mathrm{Ar}$ is $\epsilon_{\mathrm{Ar}}=8600 \mathrm{M}^{-1}$. $\mathrm{cm}^{-1}$; see also Refs. 5 and 8 . The data refer to the ionic strength $I_{\mathrm{c}}=30 \mathrm{mM}$ at $20^{\circ} \mathrm{C}$. Note that it is the ternary complex $\mathrm{NaCaAr}_{2}$ not just $\mathrm{CaAr}_{2}$ as usually thought.

\section{Discussion}

Under common experimental conditions always monovalent ions are present. There is definitely complex formation of $\mathrm{Na}^{+}$with arsenazo III $[2,3,5]$. Since $[\mathrm{Na}] \gg[\mathrm{Ar}]$, the first reaction in Table $I$ is a fast, pseudo-first-order association of Ar with $\mathrm{Na}^{+}$of the buffer followed by a slow conformational change of the complex $\mathrm{NaAr}[3,5]$. 
Because of the rather low $k_{i+}$ values the second and the third reaction in Table I must also be biphasic, e.g. conformational transitions coupled to rapid bimolecular steps. This is consistent with the fact that the total signal change from the unmixed solutions to the reacted mixture as obtained by static titrations $\left(A_{\text {stat }}\right)$, is significantly larger than the total stopped-flow amplitude $A_{\text {kin }}$ $=\sum_{i} A_{i}$. Thus an appreciable part of the reaction proceeds within the mixing time. Deconvolution corrects for the time-resolved terms in Eqn. 1 but leaves $A_{\mathrm{o}}$ much too small due to the specific conditions of the stopped-flow technique. Fig. 4 shows that the amplitude $A_{12}$ of the rapid phase relative to the total kinetic amplitude $A_{\text {kin }}$ and to the static amplitude $A_{\text {stat }}$, respectively, decreases with increasing total calcium. This means that the contributions of the complexes $\mathrm{NaAr}, \mathrm{CaAr}$, $\mathrm{NaCaAr}_{2}$ and $\mathrm{Ca}_{2} \mathrm{Ar}_{2}$ decrease with the increase in $[\mathrm{Ca}]_{0}$ whereas the concentration of the Ca-rich complex increases as seen from the increase in $A_{3} / A_{\text {stat }}$ with $[\mathrm{Ca}]_{\text {o }}$.

A satisfactory description of the data requires the inclusion of the dimerization [4-6]: $2 \mathrm{CaAr} \rightleftharpoons$ $\mathrm{Ca}_{2} \mathrm{Ar}_{2}$. Note that the numerical values of the parameters of the dimerization and of other reaction steps given by Palade and Vergara [4] refer to a different ionic strength than used here. It is obvious that the value of $k_{+}=900 \mathrm{M}^{-1} \cdot \mathrm{s}^{-1}$ characterizes $k_{+}$as an overall rate constant that includes a rapid bimolecular, diffusion-controlled association step and slower structural reorganizations within the $\mathrm{Ca}_{2} \mathrm{Ar}_{2}$ complex.

In summary, the five reactions in Table I represent a minimum reaction scheme, which satisfactorily accounts for the kinetic data. The reactions in Table $I$ are sufficient for all practical applications of arsenazo III as an $\mathrm{Ca}^{2+}$-indicator where some calibration procedure is needed.

Recently the fluorescence indicators quin 2 and fura2 have been advertised for monitoring intracellular [Ca] changes [1,9]. These new indicators have a higher selectivity for $\mathrm{Ca}^{2+}$ than arsenazo III which is known to complex also with $\mathrm{Na}^{+}$, $\mathrm{Mg}^{2+}$ and other divalent cations. Quin2 as well as fura2 are reported to exhibit a $\mathrm{Ca}$ : indicator stoichiometry of only $1: 1[10]$, thus simplifying appreciably the analysis of $[\mathrm{Ca}$ ] changes compared to the multi complex Ca-Ar system.

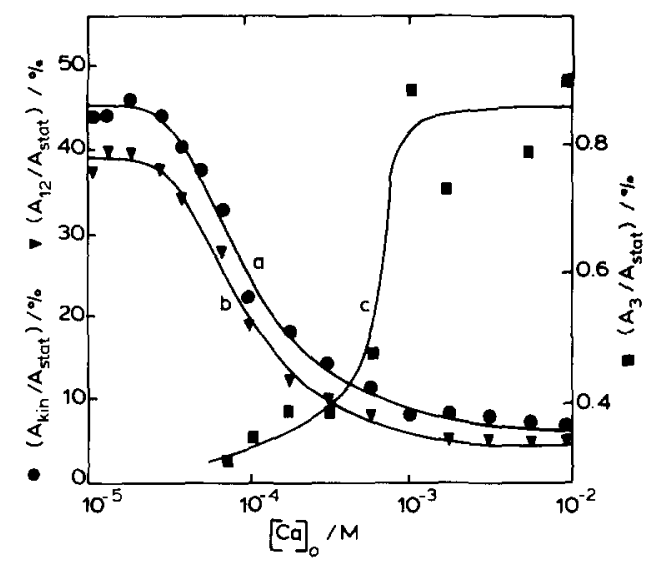

Fig. 4. Amplitude ratios: (a) $A_{\text {kin }} / A_{\text {stat }} \pm 5.2 \%$, (b) $A_{12} / A_{\text {stat }}$ $\pm 4.4 \%$, (c) $A_{3} / A_{\text {stat }} \pm 0.22 \%$ as a function of the total $\mathrm{Ca}$ concentration, respectively. The data points are mean values for the range of $[\mathrm{Ar}]_{\mathrm{o}}=10$ to $50 \mu \mathrm{M}$; Pipes buffer ( $\mathrm{pH} 7.0$ ), $20^{\circ} \mathrm{C}, I_{\mathrm{c}}=30 \mathrm{mM}$.

However, because of the higher sensitivity to $\mathrm{Ca}^{2+}$, quin2 and fura2 are not easily handled. In order to stabilize low [Ca] levels $\left(\leq 10^{-6} \mathrm{M}\right)$ frequently EDTA or EGTA have to be used as a $\mathrm{Ca}$ buffer. The Ca-binding equilibria of these chelator substances are $\mathrm{pH}$ dependent and an exact quantitative analysis is very elaborate. In addition, the equilibrium dissociation constant $K$ of the Ca-fura2 complex is strongly dependent on the ionic strength of the solution. For instance $K=$ $0.135 \mu \mathrm{M}$ at $I_{\mathrm{c}}=0.1 \mathrm{M}$ and $K=0.760 \mu \mathrm{M}$ at $I_{\mathrm{c}}=0.25 \mathrm{M}$ [11]. It is certainly not easy to buffer the ionic strength in all cases where larger changes of $\mathrm{Ca}$ concentrations occur. Therefore, arsenazo III will continue to be a useful indicator to quantitatively analyze cellular Ca-concentration changes.

\section{Acknowledgement}

The financial support of the Deutsche Forschungsgemeinschaft (grant $\mathrm{Ne} 227 / 4$ to E.N.) is gratefully acknowledged.

\section{References}

1 Tsien, R.Y., Pozzan, T. and Rink, T.J. (1984) Trends Biochem. Sci. 9, 236-266. 
2 Dorogi, P.L. and Neumann, E. (1981) Biophys. Chem. 13, 125-131.

3 Dorogi, P.L., Rabl, C.R. and Neumann, E. (1983) Biochem. Biophys. Res. Commun. 111, 1027-1033.

4 Palade, P. and Vergara, J. (1983) Biophys. J. 43, 355-369.

5 Rabl, C.R. (1985) Dissertation, University of Konstanz.

6 Rabl, C.R. and Neumann, E. (1988) in preparation.

7 Kendrick, N.C. (1976) Anal. Biochem. 76, 487-510.
8 Dorogi, P.L. and Neumann, E. (1981) Biophys. Chem. 13, 117-123.

9 Tsien, R.Y. (1983) Annu. Rev. Biophys. Bioeng. 12, 91-116.

10 Jackson, A.P., Timmermann, M.P., Bagshaw, C.R. and Ashley, C.C. (1987) FEBS Lett. 216, 35-39.

11 Grynkiewicz, G., Poenie, M. and Tsien, R.Y. (1985) J. Biol. Chem. 260, 3440-3450. 